\title{
Effects of vertical migrations by benthic microalgae on fluorescence measurements of photophysiology
}

\author{
B. Jesus ${ }^{1,2, *}$, R. G. Perkins ${ }^{3}$, M. Consalvey ${ }^{2}$, V. Brotas ${ }^{1}$, D. M. Paterson ${ }^{2}$ \\ ${ }^{1}$ Instituto de Oceanografia, Faculdade de Ciências da Universidade de Lisboa, 1749-016 Lisbon, Portugal \\ ${ }^{2}$ Sediment Ecology Research Group, University of St. Andrews, Fife KY16 8LB, UK \\ ${ }^{3}$ Marine and Coastal Environments Group, School of Earth, Ocean and Planetary Sciences, Cardiff University, \\ Cardiff CF10 3YE, UK
}

\begin{abstract}
During tidal emersion, microphytobenthic algae (principally pennate diatoms) migrate vertically within the top mm of sediment to form transient biofilms. This migration has been described as an evolutionary strategy, maximizing photosynthetic activity whilst minimizing photo-damage. This study investigated the effect of vertical migration on photophysiological parameters measured by pulse amplitude modulated (PAM) fluorescence, comparing migratory biofilms with artificially created non-migratory biofilms. Dark adaptation for $5 \mathrm{~min}$, a light response curve and 18 min dark recovery period were sequentially applied to each biofilm treatment. Vertical migration and the variable chlorophyll fluorescence signal from cells migrating to the sub-surface significantly affected all variables measured (minimum fluorescence yield, $F_{0}$, and maximum yields, $F_{\mathrm{m}}$ or $F_{\mathrm{m}}$ ' in the dark and light adapted states respectively). Maximum relative electron transport rates $\left(r E T R_{\text {max }}\right) c^{c a l c u-}$ lated from light response curves were overestimated due to downward migration by cells in avoidance of high light. Changes in $F_{\mathrm{m}}$ ' due to vertical migration caused underestimation of non-photochemical quenching (NPQ). $F_{0}$, often used as a proxy for algal biomass, was significantly lower on migrational biofilms after 5 min dark adaptation compared to non-migratory biofilms due to downward migration in the dark. This response to dark adaptation followed a temporal pattern, showing a stronger tendency for downward migration towards the end of the emersion period. Measurement of photophysiological variables of migrational microphytobenthic biofilms using variable chlorophyll fluorescence must take into account the effects of light induced vertical migration, in order to prevent errors in the calculation of derived parameters.
\end{abstract}

KEY WORDS: Endogenous rhythms · Microphytobenthos · NPQ · PAM fluorescence · Vertical migration

Resale or republication not permitted without written consent of the publisher

\section{INTRODUCTION}

Microphytobenthic (MPB) biofilms are important components of estuarine intertidal ecosystems that exhibit high rates of primary production (Brotas et al. 1995, Underwood \& Kromkamp 1999), contribute substantially to carbon flux (Middelburg et al. 2000) and also influence sediment stability (Paterson \& Hagerthey 2001). One of the major groups of microphytobenthos are biraphid pennate diatoms, which have the ability to migrate vertically within the sediment in response to environmental conditions (Admiraal 1984).
Patterns of vertical migration show diurnal and tidal rhythms (Round \& Palmer 1966, Serôdio et al. 1997, Paterson et al. 1998, Consalvey 2002), and there is evidence that migration may also be a form of behavioural photoacclimation (Paterson et al. 1998, Underwood \& Kromkamp 1999, Perkins et al. 2001, 2002, Consalvey 2002).

MPB biomass has traditionally been determined by taking samples of sediment for pigment extraction and subsequent analysis by spectrophotometry or high performance liquid chromatography, HPLC (Eaton \& Moss 1966, Brotas \& Plante-Cuny 1995). The recent intro- 
duction of pulse-amplitude modulated (PAM) fluorometers has provided an alternative, non-intrusive method for examining microphytobenthos. PAM fluorometry allows migrational behaviour to be monitored over diel and tidal periods (Perkins et al. 2001, Consalvey 2002, Honeywill et al. 2002) and endogenous rhythms to be investigated (Serôdio et al. 1997, Consalvey 2002).

In a laboratory study, Serôdio et al. (1997) showed a positive linear relationship between minimum fluorescence yield $\left(F_{0}\right)$ and the presence of MPB at the sediment surface. In situ studies have often used $F_{0}$ as a proxy for MPB biomass (Barranguet \& Kromkamp 2000, Consalvey 2002, Honeywill et al. 2002, Serôdio 2003). However, $F_{0}$ is affected by photophysiological processes such as non-photochemical quenching (NPQ) and the oxidation/reduction status of photosystem reaction centres (Consalvey et al. 2004a). Studies on diatom suspensions have also shown that $F_{0}$ might be quenched in the dark due to the maintenance of a trans-thylakoid proton gradient in darkness (e.g. Caron et al. 1987, Ting \& Owens 1993), and that the amount of NPQ may be proportional to the light intensity (Serôdio 2003, Fig.7). Thus, the time required to achieve a stable $F_{0}$ yield is dependent upon light history. As a practical compromise, the parameter $F_{0}{ }^{15}$ has been used as a substitute for the true $F_{0}$ (Honeywill et al. 2002). $F_{0}{ }^{15}$ is measured after a 15 min period of dark adaptation, which has shown a significant relationship with chlorophyll a $(\mathrm{chl} a)$ in the surface sediment (Barranguet \& Kromkamp 2000, Honeywill et al. 2002).

The main application of variable chlorophyll fluorescence techniques has been in the study of photophysiology. Several parameters are usually measured: (1) photosystem II (PSII) quantum efficiency in the dark $\left(F_{\mathrm{v}} / F_{\mathrm{m}}\right.$, where $F_{\mathrm{m}}$ is the maximum dark adapted fluorescence, and $F_{\mathrm{v}}$ is the variable fluorescence calculated as $\left.F_{\mathrm{m}}-F_{0}\right)$, (2) PSII quantum efficiency in the lightadapted state $\left(F_{\mathrm{q}}{ }^{\prime} / F_{\mathrm{m}}{ }^{\prime}\right.$, where $F_{\mathrm{m}}{ }^{\prime}$ is the maximum light adapted fluorescence yield, $F_{\mathrm{q}}{ }^{\prime}$ is the fluorescence quenched by photochemistry calculated as $F_{\mathrm{m}}{ }^{\prime}-F^{\prime}$, and $F^{\prime}$ is the fluorescence yield just prior to application of the saturation pulse used to obtain $F_{\mathrm{m}}{ }^{\prime}$; Oxborough et al. 2000), (3) relative electron transport rate ( $r$ ETR). All these parameters have the potential to offer ecologically relevant information, and are frequently used in primary productivity models (e.g. Barranguet \& Kromkamp 2000, Perkins et al. 2001, Serôdio 2003, Forster \& Kromkamp 2004, Serôdio 2004, Underwood et al. 2005). Under controlled situations $F_{\mathrm{v}} / F_{\mathrm{m}}$ can also be used to infer microalgae nutrient stress: an example is the work by Geider et al. (1993), where diatoms showed a marked decrease in this parameter under nitrate and iron starvation. Thus, it is crucial that sources of variation in the measurement of all these parameters are detected and minimized in order to improve our general knowledge of microphytobenthos ecology.

Of particular interest is the use of a high-resolution fluorescence imaging system (Oxborough \& Baker 1997, Oxborough et al. 2000, Perkins et al. 2002), which allows fluorescence measurements and real time observations of cell-turnover at the sediment surface. Using this imaging system, Perkins et al. (2002) showed substantial errors in the calculations of $r$ ETR for microphytobenthic biofilms caused by vertical migration of cells. If cell migration occurs during fluorescence measurements, calculations of $r$ ETR will be affected by a variable error dependent upon the extent and direction of migration. Therefore, it is important to investigate how vertical migration affects fluorescence measurements of MPB photophysiology and the accuracy of $F_{0}$ as a biomass proxy for microphytobenthic biomass. Two other recent studies (Forster \& Kromkamp 2004, Serôdio 2004) focused on modelling the effect of biomass and depth distribution in the integrated fluorescence measurements. Although reaching slightly different conclusions, both concluded that $r$ ETR will be overestimated if no precaution is taken to account for biomass and depth distribution, with a maximum overestimation when sub-surface biomass maximum was observed. This was confirmed by our study (see below).

This study investigated the effect of vertical migration on the measurement of variable fluorescence parameters, including $F_{0}$ and others used in the calculation of NPQ and $r$ ETR. In order to differentiate between the effects of cell migration and other photophysiological responses, an experimental system was devised in which cell migration was prevented.

\section{MATERIALS AND METHODS}

Study sites. Diatoms were collected by removing the upper $0.5 \mathrm{~cm}$ of intertidal sediments from 2 estuaries, the Tagus (Portugal, $38^{\circ} 44^{\prime} \mathrm{N}, 09^{\circ} 08^{\prime} \mathrm{W}$ ) and the Eden (Scotland, $56^{\circ} 22^{\prime} \mathrm{N}, 02^{\circ} 50^{\prime} \mathrm{W}$ ). The Tagus is a mesotidal estuary, with a mean depth of $5 \mathrm{~m}$, and an intertidal area composed mainly of mudflats that comprise 20 to $40 \%$ of the total $320 \mathrm{~km}^{2}$ area during neap and spring tidal exposure, respectively (Brotas et al. 1995). The Eden Estuary is located on the East Coast of Scotland and is a relatively small ( $4 \mathrm{~km}$ in length) and shallow (1 to $6 \mathrm{~m}$ ) macro tidal system. The shores vary from sand towards the seaward extreme of the estuary with mudflats dominating the inner estuary. Samples were collected during November 2001 and April 2002 (Eden), and during January and February 2002 (Tagus). Additionally, 2 in situ studies were carried out in 
the Tagus in March 2002. All experimental measurements were made on the $2 \mathrm{~d}$ following sampling.

Non-migratory biofilms. Non-migratory biofilms were prepared using phytotrays. These are small $(55 \times$ $55 \times 20 \mathrm{~mm}$ ) polypropylene membrane rafts with $0.3 \mu \mathrm{m}$ pores in the basal membrane (SIGMA). Phytotrays are designed for the culture of plant callous material, and the rafts float on the selected media allowing nutrients to be absorbed through the membrane. In this study, filtered seawater collected from the sample site was used. Diatom cells, collected from the estuarine sediment by the lens tissue method (Eaton \& Moss 1966), were re-suspended in seawater from the same sample site and, after removing fragments of lens tissue (by filtration through coarse muslin), the suspension was transferred into the phytotrays and allowed to settle to form a thin biofilm.

Phytotray (non-migratory) biofilms were established just prior to measurement, in order to minimise potential problems with desiccation, carbon and nutrient limitation. Also, establishment of the phytotray biofilms just prior to the measurements ensured that the diatom composition of the phytotray biofilm was as similar as possible to the cells at the sediment surface at that particular moment in time. $F_{\mathrm{v}} / F_{\mathrm{m}}$ ratio values were taken as an indicator of cell stress; high $F_{\mathrm{v}} / F_{\mathrm{m}}$ ratio values would indicate that cells were not substantially stressed by manipulation (Geider et al. 1993). Care was taken to ensure that the initial fluorescence yield was similar to its paired sediment biofilm (i.e. similar biomass). Excess seawater was removed by absorption with filter paper.

Vertical migration was prevented as cells were unable to pass through the phytotray membrane pores. The time required for cell settling together with the $31 \mathrm{~min}$ of each run were sufficient for a biofilm to form, which adhered strongly to the phytotray, such that active vigorous rubbing was required to remove the biofilm after each experiment. This indicated that during that period an EPS matrix was formed which would reduce the possibility of diatom lateral movements on a $\mathrm{cm}$ scale. This also indicated an active, healthy biofilm that bound to the phytotray, rather than a loose separate film free to move in the tray during experiments. Separate phytotrays were used as replicates, with replication varying among sites, but with a minimum of 4 (Tagus 1) and a maximum of 10 (Eden 2).

For fluorescence measurements, it was important to ensure that reflectance from the phytotrays did not significantly increase the light environments to which the biofilms were exposed to. This was achieved by comparing the down-welling light measured by a 2 pi light meter to measurements with a 4 pi meter, which measured the reflected light as well as the direct downwelling light. These measurements were made with a biofilm in the phytotray of similar biomass to that during experimental measurements. It was found that the 4 pi meter gave integrated light readings between 10 and $80 \mu \mathrm{mol} \mathrm{m} \mathrm{m}^{-2} \mathrm{~s}^{-1}$ higher than the 2 pi meter for the light range used in the rapid light curves detailed below (0 to $1100 \mu \mathrm{mol}$ photosynthetic photon flux density $[P P F D] \mathrm{m}^{-2} \mathrm{~s}^{-1}$ ). This difference was not sufficient to induce the differences observed in the results, when non-migratory biofilms were compared to migratory biofilms.

Migratory biofilms. Sediments were brought to the laboratory, homogenised by re-suspension in water from the same sample site, and spread evenly in plastic trays to a depth of approximately $2 \mathrm{~cm}$. The sediments were allowed to settle in the trays overnight, and excess overlying water was removed on the following morning during the period of virtual tide (i.e. coinciding with in situ low tide), during which time trays were exposed to $150 \mu \mathrm{mol}$ PPFD m $\mathrm{m}^{-2} \mathrm{~s}^{-1}$ from a sodium lamp, at room temperature (around $20^{\circ} \mathrm{C}$ ). The sediment surface was kept moist during the experiment by regular spraying with sample site seawater. Measurements were replicated on separate sediment trays. The number of replicates varied from 8 (Tagus 1 ) to 14 (Eden 2).

The procedures described above were used to establish laboratory migratory (sediment trays) and nonmigratory assemblages (phytotrays) for comparison with natural assemblages measured in situ (Table 1).

Variable chlorophyll fluorescence measurements. Fluorescence was measured using a Diving PAM (Walz). Fluorescence terminology followed Genty et al. (1989), van Kooten \& Snell (1990), Oxborough et al. (2000) and Honeywill et al. (2002), except for $F_{0}{ }^{5}$ and $F_{\mathrm{m}}{ }^{5}$, defined here as the minimum and maximum fluorescence yields, respectively, after $5 \mathrm{~min}$ of dark adaptation. The term fluorescence, used throughout the text, refers to variable chlorophyll fluorescence. We used $5 \mathrm{~min}$ of dark adaptation rather than the 15 min of Honeywill et al. (2002), to reduce the prob-

Table 1. Sampling sites, dates of sampling, type of biofilm studied and acronyms used throughout text

\begin{tabular}{|lrcc|}
\hline Site name & Date & Type & Acronym \\
\hline Eden 1 & 30 Nov 2001 & Phytotray & E1P \\
Eden 1 & 30 Nov 2001 & Sediment tray & E1S \\
Eden 2 & 6 Apr 2002 & Phytotray & E2P \\
Eden 2 & 6 Apr 2002 & Sediment tray & E2S \\
Tagus 1 & 31 Jan 2002 & Phytotray & T1P \\
Tagus 1 & 31 Jan 2002 & Sediment tray & T1S \\
Tagus 2 & 6 Feb 2002 & Phytotray & T2P \\
Tagus 2 & 6 Feb 2002 & Sediment tray & T2S \\
Tagus 3 & 1 Mar 2002 & Field sediment-in situ & T3F \\
Tagus 4 & 2 Mar 2002 & Field sediment-in situ & T4F \\
& & & \\
\hline
\end{tabular}


lem of potential downward vertical migration during the darkness period. The saturating pulse was $9500 \mu \mathrm{mol} \mathrm{m} \mathrm{m}^{-2} \mathrm{~s}^{-1}$ for $800 \mathrm{~ms}$. The measuring frequency was $0.6 \mathrm{KHz}$. The measuring fluorometer probe was fixed at a distance of $4 \mathrm{~mm}$ from the sample surface using a custom made holder that simultaneously covered the sample for dark adaptation (Honeywill et al. 2002). In situ measurements began immediately after tidal emersion and continued until tidal immersion. The number of temporal measurement between field sites varied due to different tidal exposure periods $(\mathrm{n}=3$ for Tagus 3 , and $\mathrm{n}=5$ for Tagus 4). Laboratory measurements were made to coincide with the time of virtual low tide on the following $2 \mathrm{~d}$ after sediment collection.

Dark adaptation and light response curves were performed as follows. The fluorescence yield just prior to the application of the saturating pulse $\left(F_{0}{ }^{\prime}\right)$ and the maximum fluorescence yield during the saturating pulse $\left(F_{\mathrm{m}}{ }^{\prime}\right)$ were measured $5 \mathrm{~s}$ after the transition of ambient light $\left(150 \mu \mathrm{mol}\right.$ PPFD m${ }^{-2} \mathrm{~s}^{-1}$ measured with the PAM light sensor) to darkness, followed by $F_{0}{ }^{5}$ and $F_{\mathrm{m}}{ }^{5}$ after 5 min of dark adaptation. Light response curves with 8 light steps $(0$ to $1100 \mu \mathrm{mol}$ PPFD $\mathrm{m}^{-2} \mathrm{~s}^{-1}$ ) were then recorded with increases in PPFD at 1 min intervals. Photosynthesislight response curves were followed by 18 min dark recovery, during which minimum and maximum fluorescence yields were measured after $10,30,60 \mathrm{~s}, 5$ and $10 \mathrm{~min}$.

NPQ was calculated from Eq. 1, modified from Bilger \& Björkman (1994):

$$
\mathrm{NPQ}=\frac{F_{\mathrm{m}}^{5}-F_{\mathrm{m}}{ }^{\prime}}{F_{\mathrm{m}}^{\prime}}
$$

$r$ ETR was calculated following Sakshaug et al. (1997) and Perkins et al. $(2001,2002)$ :

$$
r \mathrm{ETR}=\frac{F_{\mathrm{q}}{ }^{\prime}}{F_{\mathrm{m}}{ }^{\prime}} \times \mathrm{PPFD}
$$

$r$ ETR vs. light response curves were constructed using Eq. 2. The maximum rate of electron transport at light saturation $\left(r \mathrm{ETR}_{\max }\right)$, the maximum light utilisation coefficient $(\alpha)$, and the photo-inhibition parameter $(\beta)$ were calculated by iteration (Eq. 3, Platt et al. 1980):

$$
r \mathrm{ETR}=r \mathrm{ETR}_{\text {max }}\left[1-\mathrm{e}^{\left(-\frac{\alpha \times \mathrm{PPFD}}{r \mathrm{ETR}}\right)}\right] \times \mathrm{e}^{\left(-\frac{\beta \times \mathrm{PPFD}_{\text {PF }}}{r \mathrm{ETR}_{\text {max }}}\right)}
$$

The fluorescence yields over the light response curves $\left(F^{\prime}\right.$ and $\left.F_{\mathrm{m}}{ }^{\prime}\right)$ were recalculated using the recursive equations suggested by Serôdio (2004), which compensates the effect of sediment attenuation and
Table 2. Percentage change in dark-adapted maximum quantum efficiency $\left(F_{\mathrm{v}} / F_{\mathrm{m}}\right)$ between values obtained after $5 \mathrm{~min}$ dark adaptation (prior to each light response curve) and those obtained after 18 min dark recovery period. ${ }^{*} p<0.01$, ns: notsignificant (paired $t$-test for means). Statistical tests performed on original $F_{\mathrm{v}} / F_{\mathrm{m}}$ data (arcsine transformed); values in brackets are original means $(5$ min dark adaptation and $18 \mathrm{~min}$ after dark recovery, respectively)

\begin{tabular}{|lcrcr|}
\hline Source & Phytotray & $\mathrm{n}$ & Sediment & $\mathrm{n}$ \\
\hline Eden 1 & $-28 \%^{*}(0.69,0.50)$ & 8 & $-8 \%^{*}(0.73,0.67)$ & 10 \\
Eden 2 & $-22 \%^{*}(0.65,0.53)$ & 10 & $-13 \%^{*}(0.67,0.58)$ & 14 \\
Tagus 1 & $-3 \% \%^{\text {ns }}(0.70,0.68)$ & 4 & $-3 \%^{*}(0.74,0.71)$ & 8 \\
Tagus 2 & $-11 \% \%^{*}(0.66,0.59)$ & 6 & $-6 \%^{*}(0.75,0.70)$ & 12 \\
\hline
\end{tabular}

depth integration effects. Values reported by Serôdio (2004) were used as the source for the Tagus attenuation coefficients $\left(k_{\mathrm{p}}=16.9 \mathrm{~mm}^{-1} ; k_{\text {meas }}+k_{\mathrm{f}}=\right.$ $53.5 \mathrm{~mm}^{-1}$ ), and values from Consalvey (2002) were used as the source for the Eden attenuation coefficients $\left(k_{\mathrm{p}}=10.38 \mathrm{~mm}^{-1} ; k_{\text {meas }}+k_{\mathrm{f}}=32.87 \mathrm{~mm}^{-1}\right)$. These values would emphasise differences resulting from hypothetical vertical migration and differences due only to sediment attenuation and depth integration.

Temporal patterns. Fluorescence measurements were taken at the beginning and end of the emersion period on each day for each site. Non-migrational biofilms were compared with migrational biofilms. The minimum period between initial and final measurements was $3 \mathrm{~h}$ for $\mathrm{T} 3 \mathrm{~F}$ and $\mathrm{T} 4 \mathrm{~F}$, and the maximum period was $5 \mathrm{~h}$ for Eden 1 . Patterns in $F_{0}{ }^{\prime}$ and $F_{\mathrm{m}}{ }^{\prime}$ were investigated throughout the dark adaptation period ( $5 \mathrm{~min})$, the light curve ( $8 \mathrm{~min}$ ) and recovery phase (18 min), and the impact on the calculation of NPQ considered.

Statistical analysis. Data were analysed for statistical significance using Students $t$-test for unpaired samples and paired Students $t$-test for related samples. Due to

Table 3. Percentage change in fluorescence yield from $F_{0}{ }^{\prime}$ to $F_{0}{ }^{5}$ during initial $5 \mathrm{~min}$ dark adaptation for non-migratory biofilms (phytotrays) and migratory biofilms (sediment). ${ }^{*} \mathrm{p}<$ 0.01 , ns: not-significant, (paired $t$-test for means). Statistical tests performed on absolute fluorescence yield values

\begin{tabular}{|lcccr|}
\hline Site & Phytotray & $\mathrm{n}$ & Sediment & $\mathrm{n}$ \\
\hline Eden 1 & $-0.2 \%^{\mathrm{ns}}$ & 8 & $-36 \%^{*}$ & 10 \\
Eden 2 & $-3.5 \%^{*}$ & 10 & $-10 \%^{*}$ & 14 \\
Tagus 1 & $2.1 \%^{\mathrm{ns}}$ & 4 & $-10 \%^{*}$ & 8 \\
Tagus 2 & $0 \%^{\mathrm{ns}}$ & 6 & $-34 \%^{*}$ & 13 \\
Tagus 3 & - & - & $-17 \%^{\mathrm{ns}}$ & 6 \\
Tagus 4 & - & - & $-22 \%^{*}$ & 6 \\
\hline
\end{tabular}


the non-normal distribution of the proportional fluorescence data, values were arcsine transformed $\left(\mathrm{x}^{\prime}=\right.$ arc$\sin (\sqrt{\mathrm{x}})$; Zar 1999). Analysis of variance (ANOVA) was used for multiple comparisons. Homogeneity of variances was confirmed using Bartlett's test, and post-hoc analysis of differences between groups was conducted using the Scheffé test.

\section{RESULTS}

\section{Changes in photochemical efficiency $\left(F_{\mathrm{v}} / F_{\mathrm{m}}\right)$}

PSII photochemical efficiency ratios $\left(F_{\mathrm{v}} / F_{\mathrm{m}}\right)$ for sediment biofilms declined significantly between $F_{\mathrm{v}}^{5} / F_{\mathrm{m}}^{5}$ and the end of the dark recovery period ( $\mathrm{p}<$ $0.01, \mathrm{n}>7$ ) (Table 2). This was also true for 3 of the 4 non-migratory (phytotray) biofilms $(\mathrm{p}<0.01, \mathrm{n}>3)$. Sediment biofilms under laboratory conditions showed a greater recovery of photochemical efficiency than phytotray biofilms, with one exception (Tagus 1).

Phytotray biofilms and laboratory sediment biofilms showed high values of $F_{\mathrm{v}}^{5} / F_{\mathrm{m}}{ }^{5}$, which suggested that treatments did not stress the cells and that carbon or nutrient limitation was not a problem. Phytotray biofilms exhibited values between 0.62 to 0.73 and laboratory sediment biofilms showed values ranging from 0.69 to 0.74 . In situ biofilms showed lower $F_{\mathrm{v}}^{5} / F_{\mathrm{m}}^{5}$ values ranging from 0.56 to 0.59 .

\section{Changes in the fluorescence yield from $F_{0}$ ' to $F_{0}{ }^{5}$}

Fluorescence yield significantly decreased over the 5 min dark adaptation period (from $F_{0}{ }^{\prime}$ to $F_{0}{ }^{5}$ ) for all biofilms maintained in the laboratory (Table 3), except for phytotray biofilms that showed no consistent pattern and a relatively small change in yield. For in situ biofilms, the decrease from $F_{0}$ ' to $F_{0}{ }^{5}$ was significant for the T4F biofilms ( $p<0.05$, $\mathrm{n}=6$ ), but not for T3F (Table 3). Such a decrease in yield during dark adaptation strongly suggests downward migration as opposed to QA oxidation (see 'Discussion').

\section{Changes in the maximum fluorescence yield $\left(F_{\mathrm{m}}{ }^{\prime}\right.$ and $\left.F_{\mathrm{m}}{ }^{5}\right)$}

Maximum fluorescence yield increased after $5 \mathrm{~min}$ dark adaptation (from $F_{\mathrm{m}}{ }^{\prime}$ to $F_{\mathrm{m}}{ }^{5}$ ), for phytotray biofilms E1P $\left(F_{1,7}=14.3, \mathrm{p}<0.01\right)$ and T1P $\left(F_{1,4}=10.04\right.$, $\mathrm{p}<0.05)$, whereas no changes were observed for phytotray biofilms E2P $\left(F_{1,9}=2.1, \mathrm{p}=0.18\right)$ and T2P $\left(F_{1,5}=\right.$ 0.001, $\mathrm{p}=0.97$ ) (Fig. 1A). $F_{\mathrm{m}}{ }^{\prime}$ then decreased as light

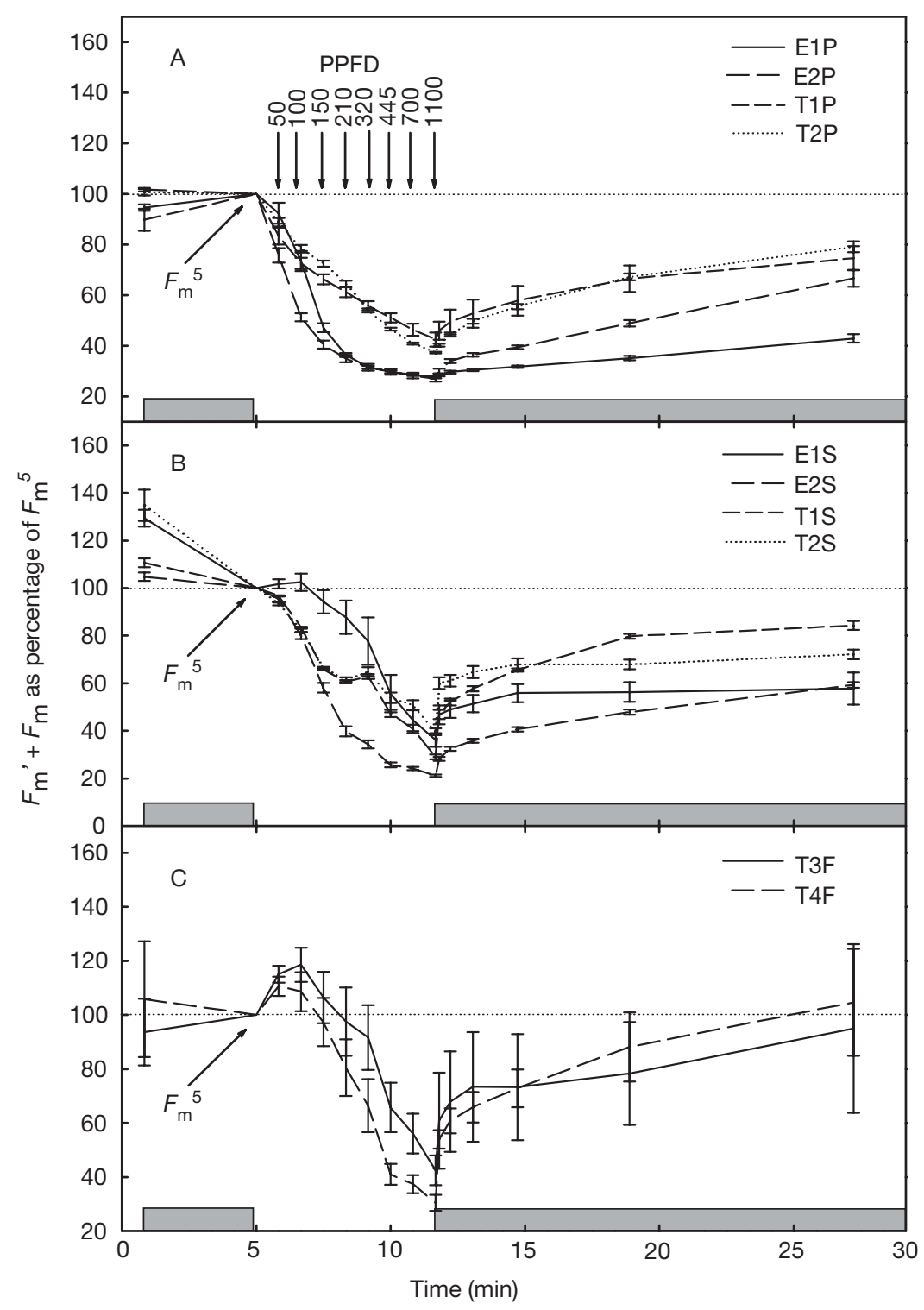

Fig. 1. Changes in $F_{\mathrm{m}}{ }^{\prime}$ and $F_{\mathrm{m}}$ expressed as a percentage of $F_{\mathrm{m}}{ }^{5}$ value; (A) phytotray, (B) sediment tray, and (C) field sediment. $F_{\mathrm{m}}^{5}$ : maximum fluorescence yield after 5 min dark adaptation, $F_{\mathrm{m}}{ }^{\prime}$ : maximum fluorescence yield measured in light-adapted state, $F_{\mathrm{m}}$ : maximum fluorescence yield measured dark-adapted state during the recovery phase. Data, mean $\pm \mathrm{SE}$, plotted over time and as a function of irradiance (PPFD m $\mathrm{m}^{-2} \mathrm{~s}^{-1}$ ); grey bars indicate periods of dark adaptation 


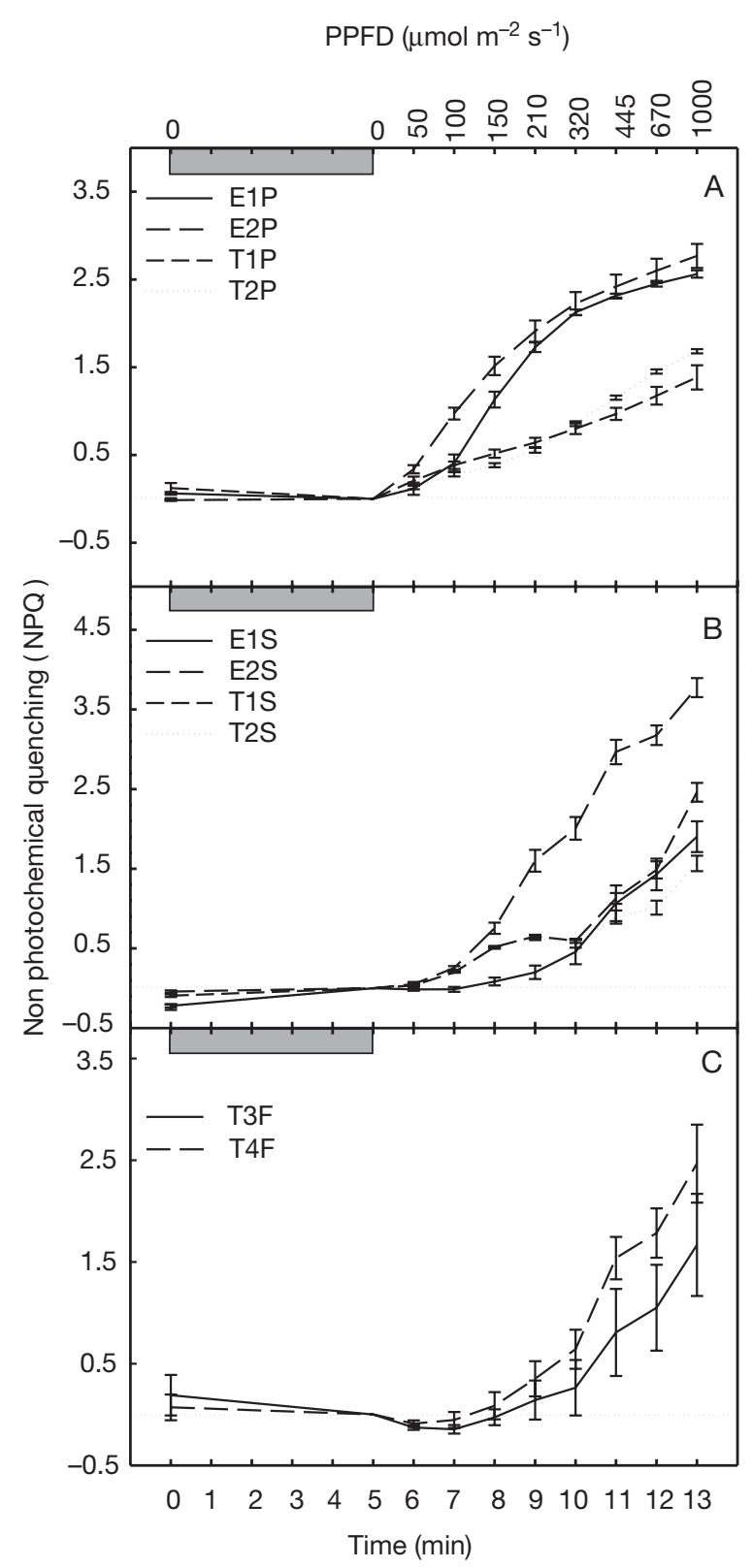

Fig. 2. Non-photochemical quenching (NPQ) after 5 min dark adaptation and during light response curves: (A) phytotray, (B) sediment tray, and (C) field sediment. Mean \pm SE, grey bars indicate darkness periods

levels increased during each of the rapid light curves. During the dark recovery phase, $F_{\mathrm{m}}$ increased rapidly over the first $2 \mathrm{~min}$ and then more slowly, with the exception of E1P that increased steadily over the whole recovery period. No biofilms showed a full recovery of $F_{\mathrm{m}}$ : all failed to reach the original $F_{\mathrm{m}}{ }^{5}$.

Migratory biofilms maintained in the laboratory all showed a significant decrease in maximum fluorescence yield from $F_{\mathrm{m}}{ }^{\prime}$ to $F_{\mathrm{m}}{ }^{5}\left(F_{1,12}=92.5, \mathrm{p}<0.001, \mathrm{E} 1 \mathrm{~S}\right.$; $F_{1,12}=4.6, \mathrm{p}<0.05, \mathrm{E} 2 \mathrm{~S}_{i} F_{1,6}=20.7, \mathrm{p}<0.05, \mathrm{~T} 1 \mathrm{~S}_{i}$
$\left.F_{1,11}=29.9, \mathrm{p}<0.001, \mathrm{~T} 2 \mathrm{~S}\right)$ (Fig. 1B). In all treatments, $F_{\mathrm{m}}$ values over the recovery period failed to reach the original $F_{\mathrm{m}}{ }^{5}$ values (Fig. 1B). In some instances, e.g. T1S and T2S biofilms, the decrease in $F_{\mathrm{m}}$ ' during the light curves showed an inflexion at around 150 to $210 \mu \mathrm{mol} \mathrm{m} \mathrm{m}^{-2} \mathrm{~s}^{-1}$. Such an inflexion may have indicated downward migration, following the more rapid decrease in $F_{\mathrm{m}}{ }^{\prime}$ that resulted from NPQ induction (see 'Discussion').

For natural biofilms (Fig. 1C), a significant increase was observed from $F_{\mathrm{m}}$ ' to $F_{\mathrm{m}}{ }^{5}$ during the dark adaptation period for T4F $\left(F_{1,4}=14.8, \mathrm{p}<0.05\right)$, whereas T3F decreased, but not significantly $\left(F_{1,5}=0.23, \mathrm{p}=0.65\right)$. During the light curves, $F_{\mathrm{m}}$ ' increased for both biofilms until a light level of $150 \mu \mathrm{mol}$ PPFD m $\mathrm{m}^{-2} \mathrm{~s}^{-1}$ was

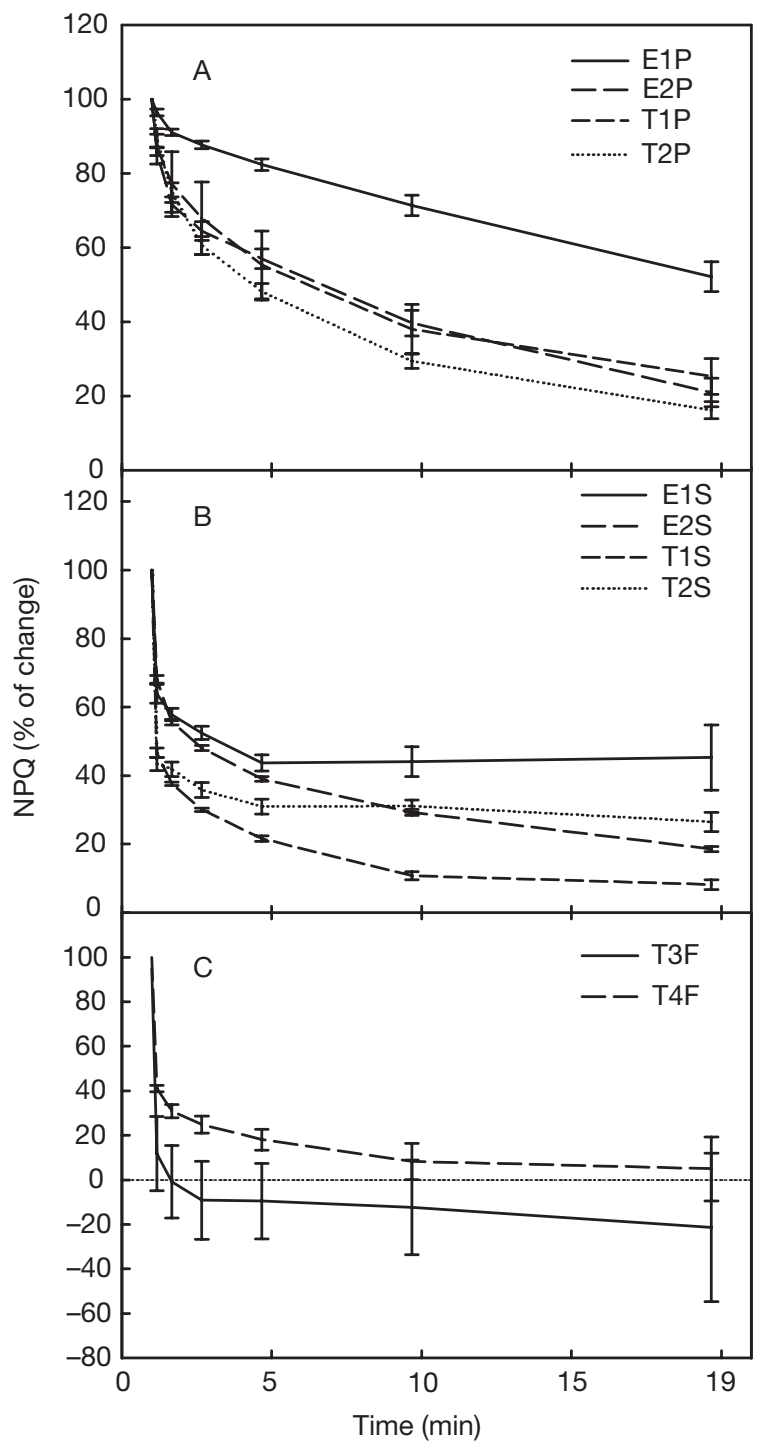

Fig. 3. NPQ during recovery phase, expressed as a percentage of the maximum value of NPQ achieved at highest irradiance during light response curves: (A) phytotray,

(B) sediment tray, and (C) field sediment. Mean $\pm \mathrm{SE}$ 
reached, before decreasing as irradiance then increased further. A rapid increase in $F_{\mathrm{m}}$ was observed during the first $3 \mathrm{~min}$ of the recovery period for both biofilms, followed by a steady increase to an $F_{\mathrm{m}}$ yield similar to $F_{\mathrm{m}}{ }^{5}$.

\section{Non-Photochemical Quenching (NPQ)}

Light curve responses

During light response curves, both phytotray and sediment biofilms showed a steady increase in NPQ (Fig. 2A,B). Eden phytotray biofilms showed a steeper gradient of change and reached significantly higher final NPQ values than the Tagus phytotray biofilms (Scheffé test, $\mathrm{p}<0.01$; mean rate of increase: Eden 0.31 NPQ relative units $\mathrm{min}^{-1}$; Tagus: $0.18 \mathrm{NPQ}$ relative units $\mathrm{min}^{-1}$ ). Phytotray biofilms from the Eden and the Tagus estuaries showed no within site variation in NPQ (Scheffé test, $p=0.39, p=0.176$, respectively; Fig. 2A). Three of the sediment biofilms (Fig. 2B) showed a slower initial increase in NPQ compared to phytotray biofilms. E1S showed no obvious increase in NPQ until an irradiance of $210 \mu \mathrm{mol}$ PPFD m $\mathrm{m}^{-2} \mathrm{~s}^{-1}$ was reached, while T1S and T2S showed an inflection point around 150 to $210 \mathrm{PPFD} \mathrm{m}^{-2} \mathrm{~s}^{-1}$. E2S was similar in behaviour to phytotray biofilms, with a final value of NPQ significantly higher than that of the other nonmigratory biofilms (Scheffé test, p < 0.01). Natural biofilms showed the same pattern in NPQ as the sediment biofilms, with no significant difference between T3F and T4F (Fig. 2C).

\section{Recovery phase}

NPQ decreased during the recovery period in phytotray biofilms (Fig. 3A). E1P exhibited a slow decrease in NPQ, whereas for the other 3 biofilms NPQ declined more rapidly during the first $2 \mathrm{~min}$ (Fig. 3A). Sediment biofilms also showed a rapid decrease in NPQ during the first 2 min (Fig. 3B). Natural biofilms showed the same general pattern (Fig. 3C), even though variation was introduced by changes in the NPQ response dependent on tidal stage (see below).

\section{Light response curves (rETR)}

The phytotray biofilms reached light saturation with a relatively stable $r$ ETR $_{\max }$ (Fig. 4). E1S and E2S sediment biofilms also showed evidence of a stable $r \mathrm{ETR}_{\max }$ after $\sim 500 \mu \mathrm{mol}$ PPFD m${ }^{-2} \mathrm{~s}^{-1}$, whereas T1S and T2S exhibited $r$ ETR that increased above $1000 \mu \mathrm{mol}$ PPFD m ${ }^{-2} \mathrm{~s}^{-1}$. In the absence of saturation, values of $r \mathrm{ETR}_{\max }$ were approximated using the last value of the light curve. $r \mathrm{ETR}_{\max }$ of sediment biofilms were therefore consistently higher than for phytotray biofilms (Table 4). Eden biofilms showed significantly lower values of $r \mathrm{ETR}_{\max }$ when compared to Tagus biofilms (Scheffé test, p < 0.01 ) and there were no difference within sites (Table 4).

\section{Temporal patterns in NPQ}

Laboratory biofilms

Patterns in NPQ during dark recovery were compared at the beginning and end of the virtual tidal emersion period. Both Tagus and Eden phytotray biofilms showed a biphasic pattern of NPQ with a rapid

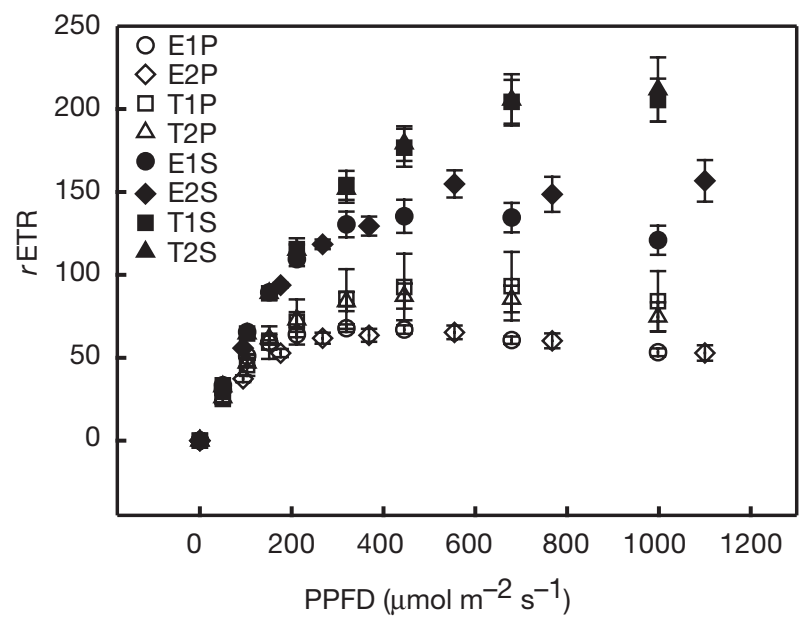

Fig. 4. Light response curves of relative electron transport rate $(r$ ETR) vs. irradiance (PPFD) obtained for laboratory sediment and phytotray biofilms. Open symbols represent phytotray biofilms, closed symbols sediment biofilms

Table 4. Maximum relative electron transport rates $\left(r \mathrm{ETR}_{\max }\right)$ and initial slope of light response curve ( $\alpha$, value of theoretical light use efficiency of PSII): comparison between non-migratory biofilms (phytotray) and migratory (sediment) biofilms. ${ }^{*} \mathrm{p}<0.01$, ns: not-significant (Student's $t$-test)

\begin{tabular}{|c|c|c|c|c|c|c|c|c|}
\hline & \multirow{2}{*}{ Phytotray } & \multicolumn{3}{|c|}{$r \mathrm{ETR}_{\max }$} & \multirow[b]{2}{*}{ Phytotray } & \multirow{2}{*}{$\bar{n}$} & \multirow{2}{*}{$x$} & \multirow[b]{2}{*}{$\mathrm{n}$} \\
\hline & & $\mathrm{n}$ & Sediment & $\mathrm{n}$ & & & & \\
\hline Eden 1 & 67 & 8 & 140 & $10^{*}$ & 0.81 & 8 & 0.87 & $10^{\mathrm{ns}}$ \\
\hline Eden 2 & 66 & 10 & 160 & $14^{*}$ & 0.52 & 10 & 0.78 & $14^{*}$ \\
\hline Tagus 1 & 94 & 5 & 219 & $11^{*}$ & 0.58 & 5 & 0.76 & $11^{*}$ \\
\hline Tagus 2 & 88 & 6 & 215 & $13^{*}$ & 0.63 & 6 & 0.74 & $13^{*}$ \\
\hline
\end{tabular}




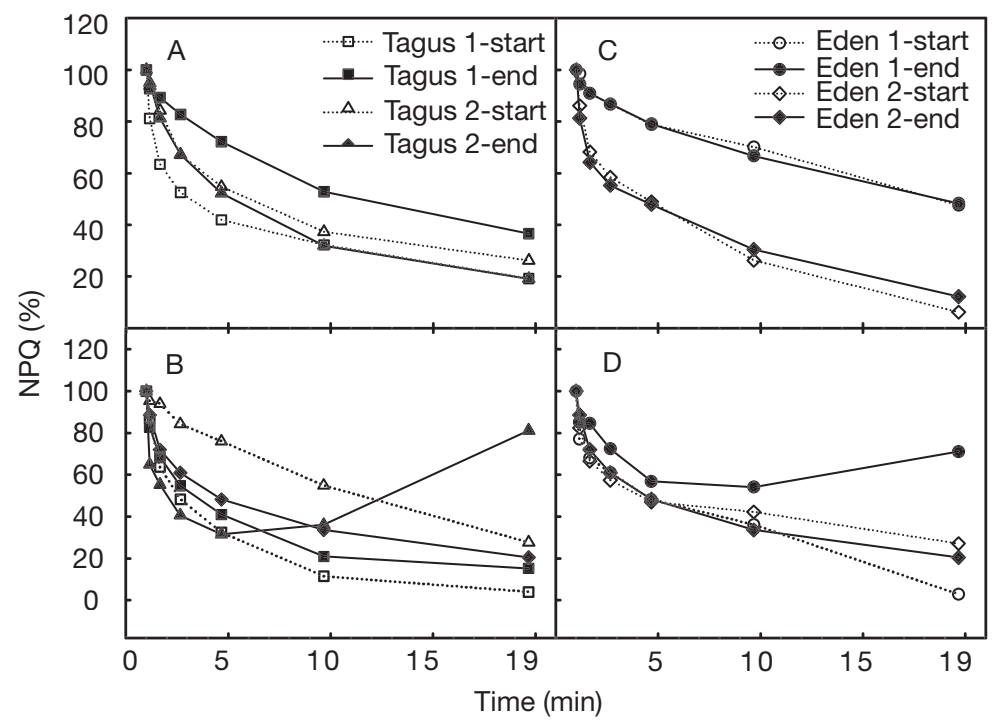

Fig. 5. NPQ during recovery phase at start (open symbols, dashed lines) and end (closed symbols, continuous lines) of emersion period, expressed as a percentage of the maximum value of NPQ achieved at highest irradiance during light response curves; (A) Tagus phytotray, (B) Tagus sediment biofilms, (C) Eden phytotray, (D) Eden sediment biofilms

decrease during the first 2 min of dark recovery, followed by a gradual decline (Fig. 5A,C). For the sediment biofilms, this pattern was also observed at the beginning of the emersion period; however, at the end of the emersion period, T2S and E1S biofilms showed a large increase in NPQ after 5 min of darkness (Fig. 5B,D).

\section{Natural biofilms}

NPQ decreased over the dark recovery period for T3F and T4F biofilms measured at the beginning of the emersion period (Fig. 6). However, at the end of the emersion period, after initial rapid decreases in NPQ during the first 3 to $4 \mathrm{~min}, \mathrm{NPQ}$ increased until the end of dark adaptation.

\section{DISCUSSION}

The regulation of photosynthesis by intertidal microphytobenthos in response to changes in ambient light can take the form of behavioural and/or physiological mechanisms. We define behavioural regulation as a relationship between light and cell position controlled by vertical migration, which optimises light availability whilst avoiding damaging high irradiances (Paterson 1994, Underwood \& Kromkamp 1999, Perkins et al. 2001, 2002). Physiological regulation includes NPQ of energy by diversion of excess light energy away from photosystem reaction centres using processes such as the xanthophyll cycle (Caron et al. 1987, Ting \& Owens 1993, Müller et al. 2001). By comparing nonmigrational systems (phytotrays) with migrational systems (sediment trays), we compared biofilms utilising NPQ without and with the ability to regulate their light environment through vertical migration.

\section{Effect of vertical migration on the estimation of fluorescence yields}

Light-induced vertical migration influenced fluorescence measurements at all stages of experimentation (dark adaptation, light curves and recovery period). Two non-migratory biofilms (E1P and T1P) exhibited a small increase in fluorescence yield from $F_{\mathrm{m}}{ }^{\prime}$ to $F_{\mathrm{m}}{ }^{5}$, which suggested a reversal of $N P Q$, whereas all migrational sediment tray biofilms (Fig. 1A,B) showed a decrease. Such a decrease in the dark can be indicative of downward migration (Perkins et al. 2001, 2002); in the dark, yield would be expected to increase through NPQ reversal. Supporting this was the observation that the decrease in $F_{\mathrm{m}}$ in sediment (migratory) biofilms was paralleled with a decrease in $F_{0}^{\prime}$ to $F_{0}^{5}$ (Table 3 )-again, NPQ reversal should result in an increase in yield (in the case of $F_{0}$ ) partly balanced by a decrease in yield due to QA oxidation.

The decrease in the minimum fluorescence yield varied in magnitude between different biofilms, suggesting that it is not always possible to use $F_{0}{ }^{5}$ or $F_{0}{ }^{15}$ to

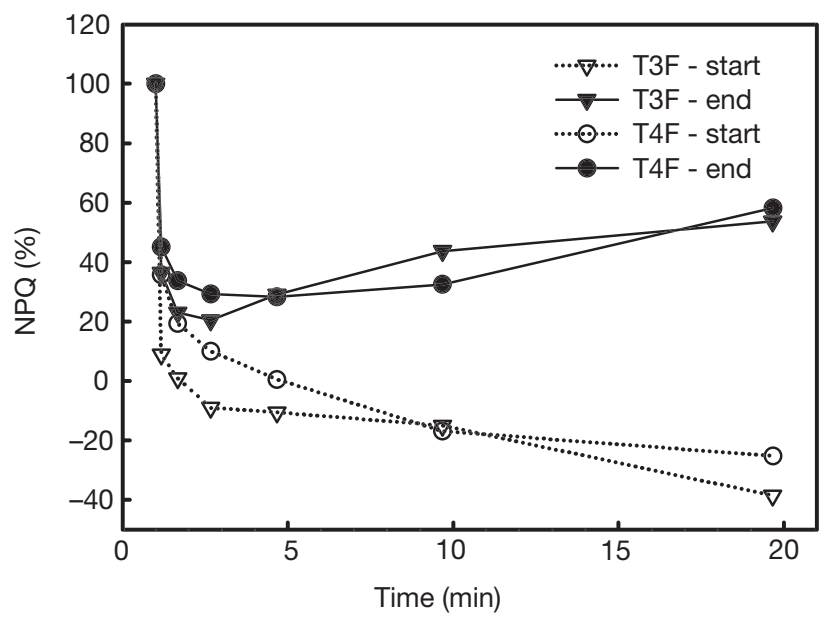

Fig. 6. NPQ for natural biofilms during recovery phase at start (open symbols, dashed lines) and end (closed symbols, continuous lines) of emersion period 
accurately estimate biomass, even though this method could still be utilised to monitor changes in surface biomass due to migration (Consalvey et al. 2004, Jesus et al. 2005) and large scale difference in biomass. These variations may reflect differences in community composition as suggested by previous authors (Serôdio et al. 1997, Perkins et al. 2001, Honeywill et al. 2002). Our conclusion is that both $F_{0}{ }^{5}$ and $F_{0}{ }^{15}$ may often underestimate biomass, dependent upon the migrational nature of the biofilm. The extent of biofilm migration will depend upon many variables including species composition, tidal stage and biofilm age, in addition to changes in the light environment (Pinckney \& Zingmark 1991, Kingston 1999, Perkins et al. 2001, Consalvey 2002, Perkins et al. 2002). Therefore, it is suggested here that fluorescence proxy measurements of biomass $\left(F_{0}^{5}\right.$ or $\left.F_{0}{ }^{15}\right)$ should be limited to follow qualitative differences in surface biomass.

During light response curves, phytotray (non-migratory) biofilms showed a rapid decrease in $F_{\mathrm{m}}$ ' with the onset of light and then a further slower decline typical of rapidly induced NPQ (Caron et al. 1987). Sediment (migratory) biofilms also initially showed a similar decline, followed by a possible inflexion in some instances (T1S and T2S) that may have indicated that vertical migration occurred to compensate for light exposure. In one case (E1S) an increase in $F_{\mathrm{m}}{ }^{\prime}$ over the first 2 steps of the light curve was observed. In the case of sediment biofilms, a decrease in yield could not be attributed with certainty to either NPQ induction or downward migration, it was likely to be a combination of both factors and dependent upon the taxa and environmental conditions. However, it seems likely that rapid induction of NPQ occurred once more, probably with slower induction of downward migration. Indeed, such a pattern in NPQ followed by downward migration has been observed for Nitzschia dubia using high resolution imaging (Paterson et al. 2003, Underwood et al. 2005).

Conversely, for sediment biofilms in which an increase in $F_{\mathrm{m}}{ }^{\prime}$ was observed, this could be the result of low light stimulating upward migration (Perkins et al. 2001) or reversal of NPQ (Kramer et al. 2004). NPQ reversal seemed unlikely in this instance, as an increase in $F_{\mathrm{m}}{ }^{\prime}$ was observed up to an irradiance of $150 \mu \mathrm{mol}$ PPFD $\mathrm{m}^{-2} \mathrm{~s}^{-1}$ and no such increase was observed for phytotray biofilms. $F_{\mathrm{m}}$ ' increased for natural biofilms (T3F and T4F, Fig. 1C) over the first irradiance steps used in the light response curves (up to $150 \mu \mathrm{mol}$ PPFD $\mathrm{m}^{-2} \mathrm{~s}^{-1}$ ), which also suggested that cells migrated towards the sediment surface. Nevertheless, the pattern of change in $F_{\mathrm{m}}$ ' for natural biofilms over the light response curve was most similar to the sediment biofilm systems, whereas non-migratory phytotray biofilms showed a more rapid decline in $F_{\mathrm{m}}$ ' over the light curve.

\section{Effect of migration on the calculation of NPQ}

NPQ during the light response curve

From Eq. 1, any change in $F_{\mathrm{m}}{ }^{5}$ or $F_{\mathrm{m}}$ ' due to changes in biomass resulting from vertical migration to or away from the sediment surface will proportionally affect the calculation of NPQ. This was evident when comparing NPQ during the light curves (Fig. 2). Phytotray biofilms down-regulated physiologically on exposure to light, as indicated by rapid increases in NPQ (Fig. 2A), whereas NPQ for the sediment biofilms and natural biofilms increased only slowly or even declined (Fig. 2B,C). The patterns observed in NPQ for the migratory biofilms may be explained by several factors. Firstly, reversal of NPQ in response to low light (Caron et al. 1987, Mouget \& Tremblin 2002). Secondly, attenuation of light by the sediment, resulting in cells being exposed to lower light than phytotray biofilms (Lassen et al. 1992, Consalvey 2002). However, this factor was strongly reduced or eliminated by using Serôdio's (2004) recursive equations to compensate for depth integration. Thirdly, a decrease in calculated NPQ due to an increase in $F_{\mathrm{m}}$ ' resulting from upward vertical migration of cells in response to low light. The E2S biofilms were the least migrational biofilms, and both Eden biofilms showed higher levels of NPQ compared to the Tagus biofilms. This may reflect a photophysiological adaptation of Tagus biofilms, being better adapted to high light and less dependant upon physiological NPQ than Eden biofilms. In terms of the cellular energy budget, migration may be less costly than photophysiological adaptation due to the relatively 'cheap' mechanism of diatom locomotion (e.g. Underwood \& Kromkamp 1999, Consalvey et al. 2004b). Some diatoms have been shown to use existing paths opened by larger diatom, thus decreasing the energy required to migrate downwards (Wenderoth et al. 2004).

\section{NPQ during the recovery phase}

The consistent decrease of NPQ in the phytotray biofilms (Fig. 3A) during the recovery phase was attributed to dissipation of the proton gradient in darkness and conversion of diatoxanthin to diadinoxanthin (Caron et al. 1987, Ting \& Owens 1993). The relatively slow decrease of NPQ in E1P may have been the result of photo-inhibitory down regulation during the light curve, due to the prevention of vertical migration. Calculated NPQ for 2 of the sediment biofilms (E1S and T2S) and for in situ migratory biofilms (Fig. 3C) showed large variation by the end of the recovery period due to the variable response of NPQ at the end of tidal exposure (see discussion below). 


\section{Light response curves ( $r$ ETR)}

The maximum relative electron transport rate $\left(r \mathrm{ETR}_{\max }\right)$ was higher for sediment than for phytotray biofilms (Table 4). This was attributed to light-induced downward vertical migration of cells at the highest light levels of the light curves. Cells that moved to the sub-surface obviously received less irradiance than surface cells due to attenuation of light by the sediment. Thus, such cells will show a higher than expected photochemical efficiency for the light level they are, in theory, being exposed to: i.e. the light level they are experiencing is over-estimated. This results in an over-estimation of $r \mathrm{ETR}_{\max }$, calculated using the surface light level (Perkins et al. 2001, 2002, Forster \& Kromkamp 2004, Serôdio 2004). The lower $r \mathrm{ETR}_{\max }$ of the phytotray biofilms provides further evidence that significant errors can be introduced in calculation of $r$ ETR due to vertical migration (Perkins et al. 2002).

An alternative hypothesis is that the measurement of $r \mathrm{ETR}_{\max }$ is accurate, due to micro-migrations of cells within the biofilm (Kromkamp et al. 1998). Kromkamp et al. (1998) suggested that diatom cells from depth replaced those at the surface, resulting in higher quantum efficiencies at high light and hence higher values of $r \mathrm{ETR}_{\max }$. However, this seems less likely than a simple downward migration of surface cells in response to the increasing light level. In addition, rapid decrease in PSII efficiency upon exposure to increasing irradiance suggests that microcycling cannot account for the high values of $r$ ETR observed. Such microcycling would have to be extremely rapid: once cells reached the surface, photochemical efficiency would decline as a result of continued exposure to the light and thus accumulation of light dose at the surface.

It is important to mention that our results were obtained after correction of the original values with Serôdio's (2004) model that compensates for fluorescence depth integration and sediment attenuation, which further strengthens the hypothesis that at higher light levels diatoms migrated down to photo-regulate exposure to light. Our results support reports by Serôdio (2004) and Forster \& Kromkamp (2004) that depth integrated fluorescence measurements overestimates the intrinsic $r E T R$, and also that a shift of cells from the surface to a sub-surface depth amplifies this overestimation. However, our observations calculate an overestimation in the rage of $108 \%$ (E1) and $144 \%$ (T2), in contrast with the maximum values estimated by other authors that ranged between $46 \%$ (Forster \& Kromkamp 2004) and 62\% (Serôdio 2004). Carbon supply was not monitored, so it could not be excluded as a source of variation; however, the phytotrays were developed for tissue growing and should have allowed nutrient re-supply through the basal membrane. The difference might be attributable to the accumulated effect of the depth integration measurement effect with the simultaneous migration downwards, even though we attempted to compensate for the depth integration effect by using the recursive equations suggested by Serôdio (2004). Although the previous models (Forster \& Kromkamp 2004, Serôdio 2004) did not account for a dynamic situation, where movement occurs during the measurement, they had already mentioned the potential effect that migrational movements might introduce in the final results.

\section{Temporal patterns}

For non-migratory biofilms, the decrease in NPQ over the dark recovery period did not vary between the beginning and end of the emersion period (Fig. 5A,C). However, 2 of the sediment biofilms (Fig. 5B,D) and 2 natural biofilms (Fig. 6) showed distinct increases in NPQ during dark recovery at the end of the emersion period. This accounted for the large variation in reversal of NPQ in biofilms in which migration could occur (Fig. 3B,C). This increase in NPQ was attributed to a decrease in $F_{\mathrm{m}}$ due to downward migration (data not shown). This showed that the migrational response to changes in light condition varied over the tidal cycle, and also that this variation may have been assemblage-specific, since not all the sediment biofilms exhibited identical migratory behaviour. The fact that phytotray biofilms (Fig. 5A,C) did not show any temporal pattern in NPQ excludes the hypothesis that the changes in the NPQ pattern were due to endogenous physiological mechanisms. Therefore, we conclude that the extent and direction of the vertical migration due to changes in light conditions were conditioned by the endogenous response of the cells to the tidal period. This supports the dual control mechanism of diatom migration proposed by Round (1981).

\section{CONCLUSIONS}

The use of PAM fluorescence to calculate photophysiological parameters (e.g. NPQ, $r \mathrm{ETR}_{\max }$ ) with migrational microphytobenthic biofilms can be strongly biased by the type of biofilm and by the timing of measurements. Data in this study have shown that vertical migration can occur in the darkness (downward or upward migration, dependent on time of emersion), at low light (upward migration), and under high light (downward migration). These effects may be reduced if the measurements are carried out at the start of an emersion period, thus reducing possible endogenous 
migrational effects. Even so, unless a comparison is made between similar migrational and non-migrational biofilms, it is not possible to quantify the effect of migrational behaviour on the calculation of photophysiological parameters. Further studies are needed to clarify the effect of light on vertical migration of microphytobenthic biofilm assemblages.

Acknowledgements. B.J. was funded by a $\mathrm{PhD}$ grant from FCT (Praxis XXI BD21634/99), and R.G.P. by a NERC grant (NER/A/S/2000/00513). This work was also funded by SATTAGIS (FCT Project No. PDCTM/MAR/15256/99) and the HIMOM project (Contract No. EVK3-2001-00043 I).

\section{LITERATURE CITED}

Admiraal W (1984) The ecology of estuarine sediment inhabiting diatoms. Prog Phycol Res 3:269-314

Barranguet C, Kromkamp J (2000) Estimating primary production rates from photosynthetic electron transport in estuarine microphytobenthos. Mar Ecol Prog Ser 204:39-52

Bilger W, Björkman O (1994) Relationships among violaxanthin deepoxidation, thylakoid membrane conformation, and nonphotochemical chlorophyll fluorescence quenching in leaves of cotton (Gossypium hirsutum L.). Planta 193:238-246

Brotas V, Plante-Cuny MR (1995) Identification et quantification des pigments chlorophylliens et caroténoides des sédiments marins: un protocolo d'analyse par HPLC. Oceanol Acta 19:623-634

Brotas V, Cabrita T, Portugal A, Serôdio J, Catarino F (1995) Spatio-temporal distribution of the microphytobenthic biomass in intertidal flats of Tagus estuary (Portugal). Hydrobiologia 300/301:93-104

Caron L, Berkaloff C, Duval JC, Jupin H (1987) Chlorophyll fluorescence transients from the diatom Phaeodactylum tricornutum: relative rates of cyclic phosphorylation and chlororespiration. Photosynth Res 11:131-139

Consalvey M (2002) The structure and function of microphytobenthic biofilms. PhD dissertation, University of St Andrews

Consalvey M, Jesus B, Perkins R, Brotas V, Paterson, DM (2004a) Monitoring migration and measuring biomass in benthic biofilms: the effects of dark/far red adaptation and vertical migration on fluorescence measurements. Photosynth Res 81:91-101

Consalvey M, Paterson DM, Underwood, GJC (2004b) The ups and downs of life in a benthic biofilm: migration of benthic diatoms. Diatom Res 19:181-202

Eaton JW, Moss B (1966) The estimation of numbers and pigment content in epipelic algal populations. Limnol Oceanogr 11:584-595

Forster RM, Kromkamp JC (2004) Modelling the effects of chlorophyll fluorescence from subsurface layers on photosynthetic efficiency measurements in microphytobenthic algae. Mar Ecol Prog Ser 284:9-22

Geider RJ, La Roche J, Greene RM, Olaizola M (1993) Response of the photosynthetic apparatus of Phaeodactylum tricornutum (Bacillariophyceae) to nitrate, phosphate, or iron starvation. J Phycol 29:755-766

Genty B, Briantais JM, Baker NR (1989) The relationship between the quantum yield of photosynthetic electron transport and quenching of chlorophyll fluorescence.
Biochim Biophys Acta 990:87-92

Honeywill C, Paterson DM, Hagerthey SE (2002) Instant determination of microphytobenthic biomass using fluorescence. Eur J Phycol 37:485-492

Jesus B, Brotas V, Marani M, Paterson DM (2005) Spatial dynamics of microphytobenthos determined by PAM fluorescence. Estuar Coast Shelf Sci 65:30-42

Kingston MB (1999) Effect of light on vertical migration and photosynthesis of Euglena proxima (euglenophyta). J Phycol 35:245-253

Kramer DM, Johnson G, Kiirats O, Edwards GE (2004) New fluorescence parameters for the determination of QA redox state and excitation energy fluxes. Photosynth Res 79:209-218

Kromkamp J, Barranguet C, Peene J (1998) Determination of microphytobenthos PSII quantum efficiency and photosynthetic activity by means of variable chlorophyll fluorescence. Mar Ecol Prog Ser 162:45-55

Lassen C, Plough H, Jorgensen BB (1992) Microalgal photosynthesis and spectral scalar irradiance in coastal marine sediments of Limfjorden, Denmark. Limnol Oceanogr 37:760-772

Middelburg JJ, Barranguet C, Boschker HTS, Herman PMJ, Moens T, Heip CHR (2000) The fate of intertidal microphytobenthos carbon: an in situ ${ }^{13} \mathrm{C}$-labelling study. Limnol Oceanogr 45:1224-1234

Mouget JL, Tremblin G (2002) Suitability of the fluorescence monitoring system (FMS, Hansatech) for measurement of photosynthetic characteristics in algae. Aquat Bot 74:219-231

Müller P, Li XP, Niyogi K (2001) Non-photochemical quenching. A response to excess light energy. Plant Physiol 125: 1558-1566

Oxborough K, Baker NR (1997) An instrument capable of imaging chlorophyll a fluorescence from intact leaves at very low irradiance and at cellular and subcellular levels of organization. Plant Cell Environ 20:1473-1483

Oxborough K, Hanlon ARM, Underwood GJC, Baker NR (2000) In vivo estimation of the photosystem II photochemical efficiency of individual microphtobenthic cells using high-resolution imaging of chlorophyll a fluorescence. Limnol Oceanogr 45:1420-1425

Paterson DM (1994) Microbiogical mediation of sediment structure and behaviour. In: Stal LJ, Caumette P (eds) Microbial mats, NATO ASI series, Vol G35. Springer Verlag, Berlin, p 97-109

Paterson DM, Hagerthey SE (2001) Microphytobenthos in contrasting coastal ecosystems: biology and dynamics. In: Reise K (eds) Ecological comparisons of sedimentary shores, Springer Verlag, Berlin, p 105-125

Paterson DM, Wiltshire H, Miles A, Blackburn J, Davidson I, Yates MG, McGrorty S, Eastwood JA (1998) Microbiological mediation of spectral reflectance from intertidal cohesive sediments. Limnol Oceanogr 43:1207-1221

Paterson DM, Perkins RG, Consalvey M, Underwood, GJC (2003) Ecosystem function, cell micro-cycling and the structure of transient biofilms. In: Krumbein W, Paterson DM, Zavarzin GA (eds) A natural history of life on earth. Kluwer Academic Publishers, Dordrecht, p 47-63

Perkins RG, Underwood GJC, Brotas V, Snow GC, Jesus B, Ribeiro L (2001) Responses of microphytobenthos to light: primary production and carbohydrate allocation over an emersion period. Mar Ecol Prog Ser 223:101-112

Perkins RG, Oxborough K, Hanlon ARM, Underwood GJC, Baker NR (2002) Can chlorophyll fluorescence be used to estimate the rate of photosynthetic electron transport within microphytobenthic biofilms? Mar Ecol Prog Ser 228:47-56 
Pinckney J, Zingmark R (1991) Effects of tidal stage and sun angles on intertidal benthic microalgal productivity. Mar Ecol Prog Ser 76:81-89

Platt T, Gallegos CL, Harrison WG (1980) Photoinhibition of photosynthesis in natural assemblages of marine phytoplankton. J Mar Res 38:687-701

Round FE (1981) The ecology of the algae, 1st edn. Cambridge University Press, Cambridge

Round FE, Palmer JD (1966) Persistent, vertical migration rhythms in benthic microflora. II. Field and laboratory studies on diatoms from the banks of the river Avon. J Mar Biol Assoc UK 46:191-214

Sakshaug E, Bricaud A, Dandonneau Y, Falkowski PG and 5 others (1997) Parameters of photosynthesis: definitions, theory and interpretation of results. J Plankton Res 19:1637-1670

Serôdio J (2003) A chlorophyll fluorescence index to estimate short-term rates of photosynthesis by intertidal microphytobenthos. J Phycol 39:33-46

Serôdio J (2004) Analysis of variable chlorophyll fluorescence in microphytobenthos assemblages: implications of the use of depth-integrated measurements. Aquat Microb Ecol 36:137-152

Editorial responsibility: Otto Kinne (Editor-in-Chief), Oldendorf/Luhe, Germany
Serôdio J, Silva JM, Catarino F (1997) Non destructive tracing of migratory rhythms of intertidal benthic microalgae using in vivo chlorophyll a fluorescence. J Phycol 33: $542-553$

Ting CS, Owens TG (1993) Photochemical and nonphotochemical fluorescence quenching processes in the diatom Pheodactylum tricornutum. Plant Physiol 101:1323-1330

Underwood GJC, Kromkamp J (1999) Primary production by phytoplankton and microphytobenthos in estuaries. Adv Ecol Res 29:93-153

Underwood GJC, Perkins RG, Consalvey MC, Hanlon ARM, Oxborough K, Baiker NR, Paterson DM (2005) Patterns in microphytobenthic primary productivity: species-specific variation in migratory rhythms and photosynthetic efficiency in mixed-species biofilms. Limnol Oceanogr 50: 755-767

van Kooten O, Snell JFH (1990) The use of chlorophyll fluorescence nomenclature in plant stress physiology. Photosynth Res 25:147-150

Wenderoth K, Marquart J, Rhiel E (2004) The big trail: many migrate at the expense of a few. Diatom Res 19:115-122

Zar JH (1999) Biostatistical Analysis, 4th edn. Prentice Hall, Upper Saddle River, NJ

Submitted: October 29, 2004; Accepted: November 24, 2005 Proofs received from author(s): May 12, 2006 